\title{
DIE ETIEK VAN LUTHER
}

ENKELE ASPEKTE

Prof. J. H. van Wyk

\section{I}

Dink ons aan die etiek van Luther dan spring onmiddellik 'n paar boeiende uitsprake van hom na vore soos oa dat Christene vanuit die gemeenskap met Christus nuwe dekaloë moet maak wat helderder as die van Moses kan wees, of dat ons in bepaalde sin vir ons naaste 'n Christus moet word. Die bydrae van Luther itot die Christelike etiek is sonder twyfel van groot betekenis en die bestudering daarvan die moeite werd. Luther is geprys as rewolusionêr en ver guis as konserwatis, hy is geëer as iemand wat weer die ware betekenis van godsdiens ontdek het toe die lewe vervloei het in etiek. Of dit egter korrek is om sy etiek as konserwatief te tipeer, soos White doen, moet betwyfel word.

Sonder om in hierdie opstel enigsins na volledigheid te streef, wil ek graag enkele sentrale temas uit die etiek van Luther uitlig en toelig. Sy etieke kan uit verskillende gesigspunte benader word, bv. vanuit geloof en werke, wet en evangelie, koninkryk van God en koninkryk van die wêreld. Dit kan getipeer word as 'n etiek van geloof, van liefde en van vryheid, selfs as 'n etiek van die kruis. Almal bied relevante invalshoeke.

Die etiek van Luther kan eerstens beskryf word as 'n etiek van geloof. Hier kom die hele teologiese veld as't ware in die gesigskring: God, Christus, Gees, sonde, genade, regverdiging, geloof.

Die mens is van nature sondaar, dws gerig op homself (cor incurvatum) en daarop uit om homself te regverdig. (Die sonde het dieselfde effek as die na binne-gekrulde horings van 'n horingsmanskaap: dis verblindend en dodelik). Daarom bestaan daar ook geen wilsvryheid ten goede nie; die mens se wil is wel vry, maar nie om Gód te soek nie, wél om homself te soek. Ongeloof is die mens se mees fundamentele sonde. En tog is die geloof in, kennis van en diens aan God (die eerste gebod!) die mees fundamentele saak ter wêreld. ${ }^{1}$ Daarby is die wet van God onmagtig om die mens te help; dit veroordeel en beskuldig veel eerder, dit dryf die mens voort, jaag hom op.

Wat bring dan die verandering en omkering teweeg? Wat maak van die mens 'n nuwe mens wat weer nuwe dade kan doen? Vir Luther geld tog baie duidelik: "Goeie werke maak nie mens goed nie, maar 'n goeie mens doen goeie werke; slegte werke maak nie mens sleg nie, maar 'n slegte mens doen slegte werke". ${ }^{2}$ Presies hier kom die evangelie ter sprake, die goeie boodskap van die genade van God, die vryspraak in Christus, die vernuwing deur die Gees - die geloof alleen (sola gratia en sola fide). Hieroor kon Luther aangrypend mooi skryf in een van sy mees beroemde geskrifte nl. Tractatus de 


\section{liberate Christiana.}

Geloof beskryf hy dan as 'n vrye en genadige geskenk van God aan die sondige en selfsugtige mens; geloof is die werk van God in ons wat die mens transformeer. Alleen deur die vreemde verdienste van Christus word ons geregverdig en kom ons in die regte verhouding tot God te staan. 'n Mens word nie geregverdig deur die regte dinge te doen nie, maar die regverdige mens doen die dinge reg; God aanvaar nie 'n persoon op grond van sy werke nie, maar die werke op grond van die persoon. In die wêreld verklaar ons 'n mens regverdig as hy reg doen maar die genade van God blyk daaruit dat Hy sondaars regverdig deurdat Hy hulle die geregtigheid van Christus toereken - wat 'n vreemde geregtigheid (iustitia aliena)! Coram Deo ontvang die mens 'n nuwe staat en kom hy in 'n nuwe relasie te staan. Dit is ware Christelike vryheid: die mens hoef homself nie meer te regverdig en te verlos nie, hy hoef net die regverdiging en verlossing in Christus te omhels. Geloof is daarom die eerste, die hoogste die heerlikste goeie werk.

Die regverdiging deur die geloof is daarom tereg beskryf as (vir Luther) die voorteken en oorsprong van Christelike optrede."

Hier vind 'n dermate radikalisering van die geloof plaas soos wat kwalik voor en selfs ná Luther te vind is; hier spreek hy uit die hart van die evangelie, uit die hart van Paulus.

Christus, en die kruis van Christus - Luther praat ook van 'n "teologie van die kruis"4 - neem 'n sentrale plek in in die teologie en etiek van Luther. Hy wou trouens niks anders wees nie as theologus crucis. Die kruisiging van Christus is wel die fondament van ons verlossing maar tog kan daar nie van 'n Christelike lewe sprake wees sonder kruisdra en seerkry, vernedering en navolging nie.

Teen die agtergrond van hierdie genade- en geloofsetiek is dit begryplik dat die etiek van Luther so anti-legalisties is, juis omdat die genade van God in Christus daarin so 'n deurslaggewende rol speel. Waar die mens homself moet verlos en self moet regverdig, soos in die outonome etiek van Kant en Marx bv, en álle vorme van humanistiese ettiek vandag, word die etiek inderdaad genadeloos. ${ }^{5}$ Van die mens word dan verwag om iets te doen - selfverlossing - wat hy in der ewigheid nooit kan vermag nie.

\section{III}

Die etiek van Luther kan egter ook beskryf word as 'n etiek van liefde. Tussen geloof en liefde is daar vir hom 'n bepaalde en onlosmaaklike verhouding: Geloof is die dader en liefde is die daad.

Dit is totaal foutief om te dink dat Luther, vanweë sy besondere beklemtoning van die regverdiging deur die geloof alleen, hom sou distansieer van die doen van goeie werke. Hy oordeel dat ons vanweë die geloof in Christus nie vry (ontslaan) is van goeie werke nie maar van 'n bepáálde méning oor die werke (nl. werkgeregtigheid). Hy verwerp nie die goeie werke nie, maar aanvaar un leer dit met sy hele hart. 
Die regverdiging maak die mens vry om ander lief te hê omdat dit die mens vry maak van selfsentrisme. Die menslike natuur is nou eenmaal so ingestel dat niemand die ander soveel gun as vir homself nie en dat elkeen soveel as wat hy kan na hom toe haal sonder om hom te bekommer wat die ander oorhou." Die genade van God en verlossing in Christus maak die mens egter vry van hierdie selfHiefde.

Oor naasteliefde, wat veral ook vyandsliefde insluit, ${ }^{7}$ kon Luther pragtige dinge skryf. Goed beskou, sê hy, leef 'n Christen alleen vir die ander en nie vir homself nie. ${ }^{8}$ Niks moet ons voor oë staan nie behalwe wat die ander nodig het en vir hom voordelig' is. ' $n$ Ware Christelike lewe is daar te vind waar die naaste ontbaatsugtig en geheel vrywillig gedien word. Die Apostel lê die volgende maatstaf tov. ons Christelike lewe aan: "Al ons werke moet op die welsyn van die naaste gerig wees". Hier verwys Luther dan veral na die voorbeeld van Christus. "Ek wil my derhalwe so te sê as 'n Christus aan my naaste gee, net soos Christus Hom aan my gegee het, en ek sal hierdie lewe niks doen behalwe wat (ek sien) vir my naaste noodsaaklik, voordelig en heilsaam is nie, aangesien ek deur die geloof oorvloed aan alles in Christus het". Ons hemelse Vader het in liefde ons te hulp gekom en ons moet eweneens so selfloos ons naaste te hulp kom en "elkeen moet vir sy naaste so te sê 'n Christus word sodat ons oor en weer in alles Christusse en Christus (vir mekaar) word, dws. ware Christen"'.

So het Luther hom skerp gekeer teen sowel selfregverdiging en selfverlossing as teen selfsug en selfliefde.

Die kriterium vir 'n goeie werk, ook in die samelewing, is nie soseer die eer van God, soos by Calvyn nie, maar wel die welsyn van die naaste.

Alle Christene is priesters, diensbaar aan God en die naaste!

\section{IV}

Ons sou ten derde die etiek van Luther ook kon tipeer as 'n etiek van vryheid. Hierdie vryheid is veelsydig. Dit dui op 'n innerlike bevryding van die selfingekeerdheid, op ' $n$ bevryding uit die greep van Satan, en op vryheid van die wet. Christelike vryheid staan voor ons in sy dubbele dimensie: 'n Christen is 'n vrye heer oor alles, sê Luther, en aan niemand onderworpe nie (vanweë die geloof); maar hy is ook 'n diensvaardige kneg van almal, onderworpe aan almal (vanweë die liefde). ${ }^{18}$

Ons moet versigtig wees, sê Gollwitzer ${ }^{11}$ en Rothuizen, ${ }^{12}$ om nie die vryheid te veel te verinnerlik en net op die siel te betrek nie. Dit is wel waar dat Luther die bevryding sterk op die innerlike mens betrek, maar vanuit die veranderde innerlike moet 'n veranderde uiterlike lewenspatroon volg. Luther se etiek van vryheid was allesbehalwe a-sosiaal en a-polities. Dit blyk uit sy vele opmerkings oor en behandelinge van sake soos die huwelik, ouerskap, arbeid, eiendom, ekonomie, die staat en oorlog - waaroor Althaus breedvoerig handel.

Omdat die Christen ' $n$ vry mens is wat lewe vanuit die genade 
van God in Christus, onder leiding van die Gees, moet hy in elke nuwe lewensituasie opnuut die wil van God ontdek. ${ }^{13} \mathrm{Hy}$ is dus geroep om in verbondenheid aan Christus nuwe dekaloë te skep, m.a.w. om van verantwoorde situasie-etiek gebruik te maak. ${ }^{14}$ So het Luther probeer waak teen sowel legalisme as libertinisme.

Die Christen bevind hom egter in sy daaglikse lewe in twee ryke of twee regimente: 'n geestelike en wêreldlike ryk, die ryk van God en die ryk van die wêreld. Oor beide regeer God, ofskoon op onderskeie wyse (met sy regterhand en met sy linkerhand). Die mensheid kan ook in twee verdeel word: hulle wat aan die koninkryk van God behoort en in Christus glo, en hulle wat aan die koninkryk van die wêreld behoort. In die een koninkryk regeer God deur sy Woord en Gees en in die ander deur die wet waardeur die sonde beteul word. Luther oordeel dan ook dat dit nie nodig is vir ' $n$ regeerder om 'n Christen te wees om te kan regeer nie: dit is voldoende om redelik te wees; in die evangelie word ons ook niks meegedeel hoe daar regeer moet word nie, maar slegs beveel dat die regering eerbiedig moet word - daarom is dit dat heidene hierin veel meer toegerus en bedrewe is as Christene!15 Hiermee het Luther geensins ontken dat dit waardevol sou wees indien alle regeerders Christene sou wees nie - ouers is juis aangeraai om hulle begaafste seuns hiervoor af te sonder. Luther is geen voorstander daarvan dat 'n Christelike minderheid 'n nie-Christelike meerderheid moet regeer nie. ${ }^{16}$

Ek sluit af met 'n kort kritiese waardering tov. enkele van die genoemde gesigspunte.

\section{Kritiek teen die twee-ryke-leer ${ }^{17}$}

Teen die spesifieke ontwerp van die Lutherse twee-ryke-leer nie teen die gedagte as sodanig nie - het daar met die loop van tyd ernstige en soms bytende kritiek ingekom, oa dat hiermee die universele koningsheerskappy van Christus in gedrang gebring word; dat die twee ryke nie net onderskei word nie maar inderdaad ook geskei word;18 dat dit 'n dubbele personele moraal in die hand werk; dat die kritiese funksie van die kerk tov. die staat te veel beperk word; dat onderdanigheid (aan die ordeninge) beklemtoon word ten koste van die verandering daarvan, die status quo eerder as hervorming aangeprys word; dat die dinamiese betekenis van die evangelie te veel geïndividualiseer is en te min "gesosialiseer" is. ${ }^{19}$ Van die skerpste kritiek het van die kant van Karl Barth gekom toe hy opgemerk het dat die Duitse volk ly aan die dwaling van die grootste Christelike Duitser, Maarten Luther, nl. sy dwaling i.v.m. die verhouding van wet en evangelie, en van wêreldlike en geestelike orde. ${ }^{20}$ Die verstommende gebrek aan geestelike weerstand by die Duitse Christene teen die aantog van die nazisme is so gewyt aan ('n verkeerde verstaan van) die twee-ryke-leer. Die katastrofe van die Tweede Wêreldoorlog het dus teologiese (Lutherse) wortels! Swak politiek volg dus logies uit swak teologie — of swak plékke van 
'n origens goeie teologie! Rothuizen wys egter daarop dat ook die omgekeerde moontlik is nl. nie net 'n te grote skeiding van kerk en staat nie maar ook 'n te grote vereenselwiging van die kerk met die staat. ${ }^{21}$ Of moet ons sê dat dit dalk 'n mengeling was van 'n te grote skeiding én 'n te grote identifisering van kerk en staat?

Die gevaar van isolasionisme en kompartementalisme is in die twee-ryke-leer inderdaad lewensgroot. Müller wys ook op die opvallende verskynsel dat die evangelie net van één koninkryk praat. ${ }^{22}$ Hy oordeel verder dat Bonhoeffer tereg die "denke in twee ruimtes" verwerp het. ${ }^{23}$ Nie in die onderskeiding self van die "twee ryke" nie maar in die vulling en uitwerking daarvan is myns insiens die groot gevare geleë — soos tans ook duidelik blyk uit die politieke debat in SA waar tussen die uiterstes van vermenging en skeiding heen en weer geslinger word, terwyl die oplossing geleë is in 'n onderskeiding van en 'n betrokkenheid op mekaar. Dit is noodsaaklik om na die veelseggende en waarskuwende woorde van 'n besoekende Lutherse teoloog - ek meen dit was Trutz Rendtorff - enkele jare gelede aan Suid-Afrika te luister toe hy die volgende opgemerk het: SA gaan deur vir 'n Calvinistiese land, maar op weinig plekke in die wêreld speel die Lutherse twee-ryke-leer so 'n groot rol as juis in SA!

\section{Kritiek teen die wet-evangelie-leer}

Vir Luther was daar 'n veel groter teenstelling en spanning tussen wet en evangelie as wat dit byvoorbeeld by Calvyn die geval was. Luther beklemtoon die usus politicus (burgerlike funksie van die wet asook die usus elenchticus (die verbryselende, aanklaende en veroordelende funksie van die wet as kenbron van die sonde), terwyl Calvyn weer die volle gewig plaas op die usus normativus (die normerende en dankbare funksie van die wet in die daaglikse lewe) - wat Luther nie geken het nie. Luther se siening van die wet is dus taamlik eensydig. ${ }^{24}$ Nie die wet nie maar die wet-as-heilsweg moet afgewys word.

Besonder opvallend is ook Luther se onchristologiese behandeling van die wet in sy Groot Kategismus. Sou dit wees omdat hy die inleidingswoorde tot die wet (dws. dat die wet ingebed is in genade en verlossing) nie ter sprake bring nie, heeltemal anders as wat Calvyn in sy Geneefse Kategismus doen? Luther volg in sy verklaring ook die orde van wet-geloof terwyl Calvyn die orde geloof-wet volg — soos ook die Heidelbergse Kategismus.

\section{Kritiek teen die geloof-werke-leer}

Kritiek is uitgespreek as sou Luther se regverdigingsleer kwiëteit en passiwiteit in die hand werk, sowel tov. die individu as tov. die samelewing. Luther het immers geleer dat 'n ware geloof vanself transformerend sou werk. In die harde praktyk van die lewe sien ons egter min of niks daarvan, soms die teendeel. Dink aan die gelowige Duitsland in die jare 1939-1945 Mens hoef ook maar net aan jouself, jou eie land en volk te dink. Juis omdat die mens simul iustus et peccator is, is dit so nodig dat hierdie ontvange geloof ook 
versorg en opgebou moet word deur die volgehoue prediking en pastoraat en kategese; geloof én geloofsvolharding is nodig. ${ }^{2 \pi}$

Die vraag ontstaan ook of Luther se politieke etiek nie te veel ingestel is op onderdanigheid en gehoorsaamheid aan die bestaande strukture nie en te min op verandering en korrigering daarvan. In hierdie opsig besit die etiek van Calvyn 'n groter vitaliteit as die van Luther: societas semper reformanda! Opvallend is ook Luther se afwysing van die boere-opstand, wat hom veel kritiek op die hals gehaal het, terwyl Calvyn (weliswaar baie versigtig) 'n interne opstand in uiterste gevalle gebillik het - maar Luther $66 \mathrm{k}^{26}$

\section{VI}

Ek sluit af met 'n sonderlinge aanhaling. Een van die skerpsinnigste tiperinge van Luther, wat, ofskoon nie in alle opsigte juis is nie, tog ' $n$ briljante samevatting is van enkele hoofmomente van sy denke, kom van niemand minder nie as (die jong) Karl Marx:

"Luther het origens die knegskap van devosie oorwin omdat hy die knegskap van oortuiging in die plek daarvan gestel het. Hy het die geloof in outoriteit afgebreek omdat hy die outoriteit van die geloof gerestoureer het. Hy het priesters in leke verander omdat hy leke in priesters verander het. Hy het die mens van die uiterlike religieusiteit bevry omdat hy religieusiteit tot die innerlike mens gemaak het. Hy het die liggaam uit sy boeie geëmansipeer omdat hy die hart in boeie geslaan het". ${ }^{27}$

\section{VOETNOTAS}

1. MA 3: $324,372.373 ;$ MA $2: 326$.

2. MA $2: 333$.

3. Althaus $1965,1^{14} \mathbf{v}$.

4. Bakker 1981, 111-16.

5. Gollwitzer 78.

6. MA 3: 367 .

7. MA $3: 349$.

8. MA $2: 336-338$.

9. Vgl MA $2: 337$ (Gollwitzer verwys na WA $7: 66$ ).

10. MA $2: 319$.

11. Gollwitzer 90.

12. Rothuizen 187.

13. White 168 .

14. Althaus $1965,37 \mathrm{v}$.

15. White $: 78$.

16. White 179-180; vgl Heyns, JA, 1982. Teologiese Eicick. Pretoria, 147-148.

17. Vgl Althaus 1965,49-87; Hoek in: Balke 1982,283-306; Duchrov; Hertz.

18. Althai is $1965,84 \mathrm{v}$. 
19. Gollwitzer 92-93.

20. Barth, Karl. 1945. Eine Schweitzer Stimme 1938-1945. Zürich, 113.

21. Rothuizen 290.

22. Müller, AD. 1963. Dämonische Wirklichkeit und Trinität. Der Atomkrieg als theologisches Problem. Gütersloh, 97.

23. Müller idem, 49.

24. Vgl Berkouwer, GC. 1949. Geloof en Heiliging. Kampen, 171v; Berkouwer, GC, 1958. De Zonde I. Kampen, 153v; Heyns Etiek aw 293-294.

25. Vgl White 182183 .

26. Althaus 1965. 133.

27. By Raddatz, FJ. 1976. Karl Marx: Een politieke biografie. Baarn, 48 (mvn MEW I: 386); vgl Gollwitzer 85.

\section{LITERATUUR}

Althaus, Paul 1965. Die Ethik Martin Luthers. Gütersloh: Mohn.

Althaus. Paul. 1972 (3), Die Theologie Martin Luthers. Gütersloh: Mohn.

Bainton, Roland, H. 1978. Here I stand: A life of Martin Luther. Nashville Tennesee: Abingdon Press.

Bakker, J. T. 1956. Coram Deo: Bijdrage tot het onderzoek naar de structuur van Luthers theologie. Kampen: Kok.

Bakker, J. T. 1981. Geloven vragenderwijs, Kampen: Kok (121-116, 129-152).

Balke W. ea. 1982. Luther en het gereformeerd protestantisme. 's-Gravenhage: Boekencentrum.

Beer, T. 1980. Der fröhliche Wechsel und Streit: Grundzüge der Theologie Martin Luthers. Einsiedeln: Johannes Verlag.

Brecht, M. 1981. Martin Luther: Sein Weg zur Reformation. Stuttgart: Calver Verlag.

Duchrov, Ulrich. 1977. Two Kingdoms - The Use and Misuse of a Lutheran i'heological Concept. Geneva.

Ebeling, Gerard. 1964. Luther: Einführung in sein Denken. Tübingen: Mohr (Engelse vertaling: Luther: An introduction to his thought: 1980 (3). Philadelphia: Fortress).

Gogarten, Friedrich. 1967. Luthers Theologie. Tübingen.

Gollwitzer, Helmut. 1976 Luthers Ethik (In sy: Forderungen der Umkehr: Beitrage zur Theologie der Gesellschaft. München: Kaiser).

Hermann, R 1967. Luthers Theologie. Berlin: Ev Verlagsanstalt.

Hertz, Karl (ed). 1967. Two Kingdoms and one world: A sourcebook in Christian Social Ethics. Minneapolis: Augsburg Publishing House.

Kuitert, H. M. Aug. 1982. Ethiek van Lutherse Huize: Thielicke en Rendtorff: Een plaatsbepaling. Geref. Theologisch Tijdschrift 82 (3): 161-169.

Lohse, B. 1981. Martin Luther: Eine Einführung in sein Leben und sein Werk. Müchen.

Luther: Martin Luther: Ausgewählte Werke (Borcherdt, H. H. \& Merz, G.), 1-7, 1934-1938 (2). München: Kaiser (aangehaal as Munchener Ausgabe = MA). 
Obcrman, H. A. 1982. Luther: Mensch zwischen Gott und Teufel. Berlin: Severin \& Siedler.

Pinonmaa, L. 1964. Sieg des Glaubens: Grundlinien der Theologie Luthers. Göttingen: Vandenhoeck \& Rupert.

Rogge. $J_{i}$ 19. Martin Luther. Berlin: Ev Verlagsanstalt.

Rothuizen. G. Th. 1978. Kerk en politiek: Matteüs $20: 25-28$ en de Twee rijkenleer (In De Knechtgestalte van Christus - Studies aangeboden aan II N. Ridderbos. Kampen: Kok, 179-193).

Scharffernoth, Gerta. 1982. Den Glauben ins Leben ziehen... München: Kaiser (veral oor die twee-ryke-leer).

Von Loewenich. W. 1954 (2). Luthers theologia crucis. München.

White, R.E.O. 1981. Luther: Concervative Reformed Moraliiy (In sy: The Changing Continuity of Christian Ethics II: The Insights of History. Exeter: Paternoster, 153-183).

Zimmerman, J. Aug. 1964. The Christian life in Luther and Calvin. The Luthern Quarterly XVI (3): 222-230.

Van die volgende geskrifte kon ek ongelukkig nie volledige besonderhede bekom nie:

Betcke, W. 1934: Luthers Sozialethik.

Dittrich, O. 1930. Luthers Ethik.

Köstlin, Julius. 1901. Luthers Theologie I \& II.

Olsson, H. 1934. Grundprobleme mit Luthers Sozialethik. 